\author{
E. J. Müller \\ M. Wick \\ O. Russe \\ G. Muhr
}

\section{Management of odontoid fractures in the elderly}

Received: 28 October 1998

Revised: 16 April 1999

Accepted: 4 May 1999
E. J. Müller $(\varangle) \cdot$ M. Wick · O. Russe G. Muhr

Dept. of Surgery and Traumatology, BG-Kliniken Bergmannsheil, Ruhruniversität,

Bürkle-de-la-Camp Platz 1, D-44789 Bochum, Germany Fax: +49-234-330 734

\begin{abstract}
Odontoid fractures are frequent in patients over 70 years of age, and in patients over 80 years of age they form the majority of spinal fractures. In a retrospective analysis of 23 geriatric (> 70 years) patients with a fracture of the odontoid, we compared some of the clinical features to a contemporary series of patients younger than 70 years of age. Whereas in the younger patients high-energy trauma accounted for the majority of the fractures, low-energy falls were the underlying cause in $90 \%$ of the odontoid fractures in the elderly. In contrast to the younger age group, in elderly patients predominantly type II fractures (95\%) were identified. Anterior and posterior displacement were recorded with equal frequency on the first postinjury radiograph in the younger age group, whereas in geriatric patients displacement was mainly posterior. The number of associated injuries was significantly higher in younger patients. There was no difference in
\end{abstract}

the occurrence of neurological deficits (13\%) between the two age groups, and neurological compromise was mainly related to posterior dislocation of the odontoid in both groups. The overall complication rate was significantly higher in elderly patients (52.2\% vs $32.7 \%$ ), with an associated in-hospital mortality of $34.8 \%$. Loss of reduction and non-union after non-operative treatment, a complicated postoperative course and complications due to associated injuries accounted primarily for this high complication rate. Elderly patients with a fracture of the odontoid are a high-risk group with a high morbidity and mortality rate. An aggressive diagnostic approach to detect unstable fractures and application of a halo device or early primary internal stabilisation of these fractures is recommended.

Key words Cervical spine . Odontoid · Fracture - Treatment . Patient's age

\section{Introduction}

Fractures of the odontoid are not infrequent and the incidence varies between $7 \%$ and $15 \%$ of all cervical spine fractures. The treatment of the different types of fracture of the odontoid still remains controversial and no single method of management has become universally accepted. In the literature the reported rate of non-union is as low as $2.4 \%$ and as high as $82 \%$ for all types of injury $[1,3,6,7$,
$13,15,19,22,23]$. Possible causes for the high incidence of non-union have been studied, and apart from pathomorphological findings that may account for non-union like the mechanism of injury, fracture type, blood supply, traction applied, reduced trabecular bone volume at the base of the dens [2], displacement and diastasis etc., the rate of non-union has also been attributed to the patient's age [22]. In persons aged 70 years and over, odontoid fractures are the most common individual fractures in the cervical spine, and in the age group 80 years and over, 
odontoid fractures comprise the majority of fractures of the spine [20]. However, little attention has been paid in the literature to the management of fractures of the dens in the elderly and the associated complications. Pepin et al. [18] concluded, after a retrospective analysis of 19 patients over 60 years old with a fracture of the odontoid, that they would favour a more conservative approach to elderly, more sedentary patients. However, Bednar et al. [5], after performing a prospective analysis to determine the influence of early operative stabilisation of type II fractures in the elderly, concluded that an aggressive primarily applied surgical management protocol can significantly decrease and potentially eliminate in-hospital mortality.

This article reports the results of a retrospective analysis of fractures of the odontoid in patients over 70 years of age with regard to the aetiology, the natural history and the treatment of fractures of the dens in this age group. Some of the clinical features are compared to those of a contemporary series of patients less than 70 years of age.

\section{Materials and methods}

Between 1984 and 1993, 77 patients with acute fractures of the odontoid were treated at our institution. Twenty-three $(29.9 \%)$ of these (13 women and 10 men) were older than 70 years of age at the time of injury (average age 80.9 years; range 71-96) (see Fig. 1). Road traffic accidents accounted for $2(8.7 \%)$ of the 23 fractures (both patients, a pedestrian and a cyclist, were hit by a car). The remaining 21 fractures $(91.3 \%)$ were caused by minor falls. Eleven patients were referred from other hospitals, with an average delay of 9.6 days (range 1-28 days). In the younger age group, 54 patients (16 women and 38 men) with an average age of 47.6 years (range $15-69$ years), $31(57.4 \%)$ of the injuries were due to road traffic accidents, a fall accounted for 18 fractures $(33.3 \%)$ and in five patients $(9.3 \%)$ the exact mechanism of injury could not be evaluated.

The diagnosis was established radiographically, including standard anteroposterior, lateral and open-mouth radiographs. Conventional tomography and lateral flexion/extension views were used to confirm the diagnosis and the stability of the injury when necessary.

The stability and status of healing of the fracture were determined radiographically. Specific criteria for osseous union included evidence of trabeculation across the fracture site and absence of move-

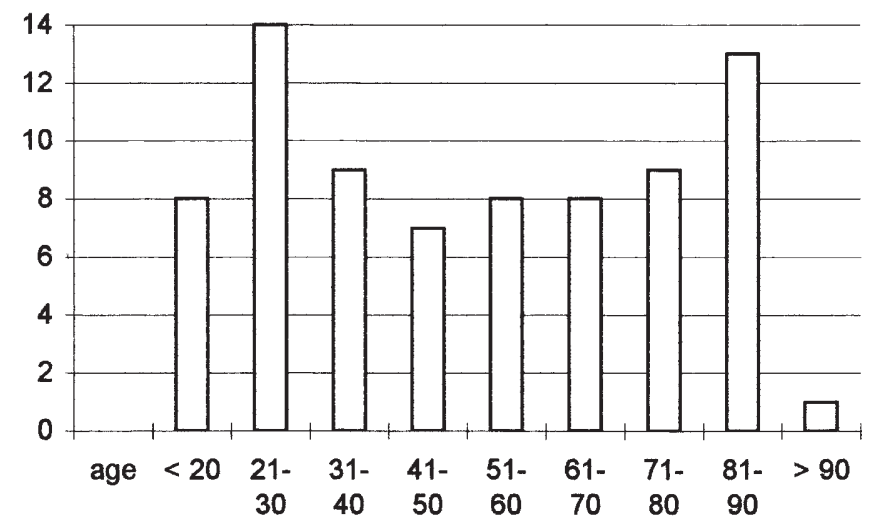

Fig. 1 The age distribution demonstrates a peak incidence in the third decade and another peak in the ninth decade
Table 1 Classification of the fractures according to a modified scheme of Anderson and d'Alonzo [3]

Fracture classification Geriatric patients Younger patients

Type I

Type II

Undisplaced

Ant. displacement

Ant. angulation

Post. displacement

Type III

Undisplaced

Ant. displacement

Rotation

$22 \quad 40$

$16 \quad 24$

15

3

3
8

14

11

2

1

Table 2 Overview of the treatment of all fractures

\begin{tabular}{|c|c|c|c|c|}
\hline Treatment & Type I & Type II & Type III & Total \\
\hline Operative & & 20 & 2 & $22(28.6 \%)$ \\
\hline Ant. screw fix. & & 20 & 1 & 21 \\
\hline Post. fusion $\mathrm{C} 1 / 2$ & & & 1 & 1 \\
\hline Non-operative & & 42 & 13 & $55(71.4 \%)$ \\
\hline Halo device & & 21 & 8 & 29 \\
\hline Cervical orthosis & & 19 & 6 & 25 \\
\hline Minerva PoP & & 1 & & 1 \\
\hline
\end{tabular}

ment on lateral flexion-extension views. When necessary, conventional tomograms were used to establish or confirm union of the fracture.

The fractures were classified according to the scheme of Anderson and d'Alonzo [3] into three groups; they were further distinguished according to the amount and direction of angulation and the displacement (see Table 1). Whereas in geriatric patients type II injuries were identified predominantly $(95.7 \%)$, there was a higher incidence of type III injuries $(25.9 \%)$ in younger patients.

Neurological impairment related to the fracture of the odontoid occurred in three patients $(13 \%)$ older than 70 years, in all three the loss of function was graded as a Frankel D [10]. Significant posterior displacement on initial radiographs was noted in two of the three patients with neurological deficits. In the younger age group neurological deficits were noted in seven patients (13\%): in three patients the deficit was graded as a Frankel D, in two as a grade C, in one as grade B and in the remaining as grade A. Significant posterior displacement on initial radiographs was documented in five of the seven patients with neurological deficits.

An associated fracture of the ring of the atlas was notified in 13 patients $(56.5 \%)$ older than 70 years; no associated injury in the lower cervical spine was identified. Head trauma occurred in three patients $(13 \%)$, loss of consciousness was documented in two patients, a fracture of the skull was recorded in another patient. Associated isolated fractures of the extremities were noted in four patients, both patients $(8.7 \%)$ who were involved a road traffic accidents had sustained multiple injuries with an injury severity score (ISS) [4] of 50 and 43 respectively. Due to the severity of the associated injuries (ISS 50), one patient died within $48 \mathrm{~h}$ after the trauma.

In ten patients $(18.5 \%)$ who were younger than 70 years, an associated fracture of the ring of the atlas could be identified; and there were two $(3.6 \%)$ associated fractures in the lower cervical spine. Concomitant head trauma was documented in 24 patients $(44.4 \%)$, four of these had a fracture of the skull. Isolated extremity fractures 
Table 3 Primary treatment of odontoid fractures in geriatric patients
Table 4 Primary treatment of odontoid fractures in younger patients

\begin{tabular}{|c|c|c|c|c|c|c|c|c|}
\hline & \multirow[t]{2}{*}{ Type I } & \multicolumn{3}{|l|}{ Type II } & \multicolumn{3}{|l|}{ Type III } & \multirow[t]{2}{*}{ Total } \\
\hline & & $\begin{array}{l}\text { Non-dis- } \\
\text { placed }\end{array}$ & $\begin{array}{l}\text { Dis- } \\
\text { placed }\end{array}$ & Total & $\begin{array}{l}\text { Non-dis- } \\
\text { placed }\end{array}$ & $\begin{array}{l}\text { Dis- } \\
\text { placed }\end{array}$ & Total & \\
\hline $\begin{array}{l}\text { Operative } \\
\text { Ant. screw fix. } \\
\text { Post. fusion C1/2 }\end{array}$ & & 5 & & 5 & & & & $\begin{array}{l}5(21.7 \%) \\
5\end{array}$ \\
\hline $\begin{array}{l}\text { Non-operative } \\
\text { Halo device } \\
\text { Cervical orthosis } \\
\text { Minerva PoP }\end{array}$ & & 11 & $\begin{array}{l}3 \\
3\end{array}$ & 17 & 1 & & 1 & $\begin{array}{r}18(78.3 \%) \\
3 \\
15\end{array}$ \\
\hline Total & & 16 & 6 & 22 & 1 & & 1 & \\
\hline
\end{tabular}

\begin{tabular}{|c|c|c|c|c|c|c|c|c|}
\hline & \multirow[t]{2}{*}{ Type I } & \multicolumn{3}{|l|}{ Type II } & \multicolumn{3}{|l|}{ Type III } & \multirow[t]{2}{*}{ Total } \\
\hline & & $\begin{array}{l}\text { Non-dis- } \\
\text { placed }\end{array}$ & $\begin{array}{l}\text { Dis- } \\
\text { placed }\end{array}$ & Total & $\begin{array}{l}\text { Non-dis- } \\
\text { placed }\end{array}$ & $\begin{array}{l}\text { Dis- } \\
\text { placed }\end{array}$ & Total & \\
\hline Operative & & & & 16 & & & 1 & $17(31.5 \%)$ \\
\hline Ant. screw fix. & & 7 & 9 & & & & & 16 \\
\hline Post. fusion $\mathrm{C} 1 / 2$ & & & & & & 1 & & 1 \\
\hline Non-operative & & & & 24 & & & 13 & $37(68.5 \%)$ \\
\hline Halo device & & 14 & 4 & & 6 & 2 & & 26 \\
\hline Cervical orthosis & & 2 & 3 & & 5 & & & 10 \\
\hline Minerva PoP & & 1 & & & & & & 1 \\
\hline Total & & 24 & 16 & 40 & 11 & 3 & 14 & \\
\hline
\end{tabular}

were seen in 11 patients, and 9 patients $(16.7 \%)$ had sustained multiple associated injuries with an ISS of 32 on average (range 19-50).

Because of the retrospective character of this study, with several surgeons being involved over the long observation period, there was no definitive treatment protocol for these injuries. The decision for the different treatment options was solely based on the individual experience of the surgeon in charge.

For more than two-thirds of all fractures, non-operative methods were selected for primary treatment. Primary operative treatment was performed on less than one-third of fractures, the majority of them being type II injuries (see Table 2).

In patients older than 70 years, non-operative treatment was the method of choice for $18(78.3 \%)$ patients, whereas for the remaining 5 patients primary internal fixation was chosen as the appropriate treatment (see Table 3).

In the younger age group, primary internal fixation was selected as the treatment of choice in nearly one-third $(31.5 \%)$ of the patients; anterior screw fixation of the odontoid was the predominant prodecure. In the remaining two-thirds of patients $(68.5 \%)$ non-operative treatment was chosen; a halo device was applied in $70 \%$ of these fractures (see Table 4).

\section{Results}

The overall complication rate in elderly patients was $52.2 \%$ (12/23; however, there were 14 complications in these 12 patients) (Table 5 ).

Loss of reduction with consecutive persistent instability was noted in four patients treated primarily with a Philadelphia collar, all four fractures were undisplaced on
Table 5 Complications and secondary procedures in geriatric patients. There were 14 complications in 12 patients. Loss of reduction and non-union occurred in primary undisplaced type II injuries treated with a Philadelphia collar $(5 / 11)$

\begin{tabular}{lll}
\hline & $\begin{array}{l}\text { Non-operative } \\
(n=18)\end{array}$ & $\begin{array}{l}\text { Operative } \\
(n=5)\end{array}$ \\
\hline Loss of reduction & 4 & 1 \\
Non-union & 1 & 2 \\
Death & 6 & \\
Secondary procedures & 5 & \\
\hline
\end{tabular}

initial x-ray evaluation. Secondary anterior screw fixation was performed in all four patients. In one of these patients with a type II fracture of the odontoid a compression of the vertebral artery with neurological impairment occurred. Traction with Crutchfield tongs was applied immediately, and after reducing the fracture neurological symptoms subsided. Direct anterior screw fixation was performed the following day. The postoperative course was uneventful and the patient recovered completely.

In another patient whose undisplaced type II injury was also treated with a cervical orthosis, non-union of the odontoid was confirmed after 3 months, and secondary posterior transarticular screw fixation was performed.

There were six deaths in the non-operative group $(37.5 \%)$. As already mentioned, one polytraumatised pa- 
Table 6 Complications and secondary procedures in younger patients

\begin{tabular}{lll}
\hline & $\begin{array}{l}\text { Non-operative } \\
(n=37)\end{array}$ & $\begin{array}{l}\text { Operative } \\
(n=17)\end{array}$ \\
\hline $\begin{array}{l}\text { Pulmonary embolism } \\
\text { Loss of reduction }\end{array}$ & 1 & 2 \\
$\begin{array}{l}\text { Malpositioning of screws } \\
\text { Non-union }\end{array}$ & 5 & 1 \\
Pin infection & 3 & \\
Death & 3 & 1 \\
Secondary procedures & 1 & 2 \\
\hline
\end{tabular}

tient (ISS 50) died within $48 \mathrm{~h}$ after the trauma due to the severity of the injuries. All three patients with associated neurological impairment also died during the course of treatment: one died of cardiac arrest, one developed severe pneumonia with respiratory insufficiency, and the third, whose fracture was treated with a halo fixator, died because of cardiac decompensation.

Another two patients of this group died after undergoing secondary operative procedures due to the complicated postoperative course: one patient suffered from severe pneumonia, the other died of cardiac arrest.

In the group with primary internal stabilisation of the fracture, two deaths occurred (40\%). One 86-year-old patient died from cardiac arrest during the postoperative course, the second patient, a 77-year-old woman, developed severe pneumonia with respiratory insufficiency. One patient suffered from cardiac insufficiency postoperatively.

Another undisplaced type II fracture, primarily treated with direct anterior screw fixation went on to non-union. Lateral flexion-extension views 3 months postoperatively did not reveal any instability or loosening of the screws, and no further treatment was undertaken.

In the younger patients the overall complication rate was $32.7 \%$ (17/54) (Table 6). In the non-operative group, one patient suffered from pulmonary embolism, while persistent instability/failure of fixation associated with nonoperative treatment was noted in five patients (13.5\%). Of these five, one was an undisplaced type III fracture primarily treated with a Philadelphia collar, three were initially displaced type II injuries treated with a halo device, and one a displaced type II fracture treated with a Philadelphia collar. Secondary procedures had to be performed in all five cases. Pin infection associated with a halo fixator was noted in three patients, and malunion/non-union occurred in another three patients. Failure of fixation after operative stabilisation occurred in two patients, one after anterior screw fixation of a type III fracture and the other after anterior screw fixation of a type II fracture. After secondary operative stabilisation, the course was uneventful in both cases. In another patient malpositioning of a screw after anterior screw fixation was noted on postoperative roentgenographs. There were two deaths $(3.7 \%)$ in this group; both patients were older than 60 years and both had neurological deficits - Frankel A in one, and Frankel D, associated with multiple injuries (ISS 43), in the other.

Eight patients over the age of 70 were followed up, with an interval of 44.3 months (range 18-105 months). As already mentioned, eight patients died in the post-traumatic period. Another three patients died after completion of the treatment, due to reasons not related to the odontoid fracture, three patients were lost to follow-up and one patient refused to attend.

In two of the eight patients who were followed up, primary anterior screw fixation was performed; the remaining six were treated non-operatively with a Philadelphia collar, one of whom underwent secondary operative stabilisation because of non-union.

Radiological evaluation demonstrated solid fusion of the odontoid fracture in four of the five cases treated nonoperatively, one fracture was malunited $(<3 \mathrm{~mm}$ displacement, $<10^{\circ}$ angulation); pseudarthrosis after anterior screw fixation was seen in one case without instability on flexion-extension views.

Four of the eight patients were completely free of pain at follow-up, three had been treated non-operatively, and one with anterior screw fixation. Three patients suffered from intermittent neck pain, in two cases the fracture was malunited after non-operative treatment, and pseudarthrosis after anterior screw fixation was evaluated in the other patient. One patient whose fracture was united complained about painful neck motion. No neurological deficits were noted.

In the younger age group, 41 patients were followed up at an interval of 47.2 months on average (range 9108 months). Eight patients did not respond, three patients refused to come and two died after completion of the treatment due to reasons not related to the odontoid fracture. At follow-up, 12 patients were free of pain, three of the fractures had been treated with primary anterior screw fixation, the remaining nine had been treated non-operatively. In one patient $\mathrm{x}$-ray evaluation demonstrated a pseudarthrosis without signs of instability on flexion-extension views, in all other fractures solid fusion in an anatomic position was documented. The remaining 29 patients complained of intermittent neck pain and painful neck motion. In 16 of these the fracture was malunited with significant angulation and/or displacement of the dens fragment. Neurological deficits were evaluated in four patients, all four were posttraumatic lesions. Three of the four patients had improved by at least one grade on the Frankel scale.

\section{Discussion}

In contrast to the findings of other authors, who documented either that odontoid fractures were evenly distributed across the age range [3] or that they were more com- 
mon in the young or middle aged [7, 22], this study demonstrates a peak incidence in patients in the third decade and another peak in the ninth decade of life. This correlates well with the data of Pepin et al. [18], who found a similar age distribution. Ryan and Henderson [20] in their epidemiological study also demonstrated that fractures of the odontoid were the most common individual fracture of the cervical spine in persons aged 70 years and older. In this study $30 \%$ of all patients were older than 70 years at the time of injury.

Whereas in the younger individuals high-energy trauma (e.g. road traffic accidents, falls from a significant height, etc.) accounted for the majority of injuries, this is the exception in patients over the age of $70[5,12,18,21]$. In our study more than $80 \%$ of the injuries in patients older than 70 years were attributed to a simple low-energy fall, in the younger patients more than $60 \%$ of the injuries were due to road traffic accidents. In accordance with the different mechanism of injury associated injuries were more common in the younger age group, with a higher incidence of concomitant head trauma ( $44.4 \%$ vs $13 \%$ ) and multiple trauma $(16.7 \%$ vs $8.7 \%)$. The incidence of associated fractures of the ring of the atlas was $29.9 \%$ for all patients. This is lower than has been reported by other authors [9, 17]; however, comparing the two age groups the incidence was significantly higher in elderly patients $(56.5 \%$ vs $18.5 \%$ ). This finding may also be related to the different mechanism of injury, where in low-energy falls a direct anterior or oblique anterior blow to the head results in a hyperextension, with the posterior ring of the atlas being pressed against the occiput. This hypothesis is supported by Mouradian et al. [17] as well as by Doherty et al. [9], who demonstrated in biomechanical studies that type II fractures result from lateral bending and extension forces; for type III injuries pure extension was found to be the mechanism of injury.

Pepin et al. [18] in their series identified more type II odontoid fractures in younger patients, whereas in this study type II fractures were more frequent in patients older than 70 years. This finding corresponds to the data of Ryan and Taylor [21] as well as to the results of Bednar et al. [5], who found a similar fracture distribution to ours. Regarding the direction of displacement recorded on the first postinjury radiograph, in the younger age group anterior and posterior displacement occurred with equal frequency, whereas in patients older than 70 years displacement was mainly posterior. A similar displacement pattern was found by Bednar and co-workers [5]. Pepin et al. [18] identified a higher incidence of anterior displacement in the younger age group and a higher incidence of posterior displacement in the older age group. However, the direction of displacement seen on initial radiographs may not document the trauma-related displacement, but rather the displacement that occurred after the injury. Supine positioning of the patient might convert an unstable fracture of the odontoid with posterior displacement into a fracture with anterior displacement. This phenomenon has been documented in a paediatric patient with this type of injury [14].

The reported incidence of neurological deficits in fractures of the odontoid varies between $3 \%$ and $25 \%$ [1, 3, $19,23]$. In this study neurological deficits were documented in $13 \%$ of the cases, and there was no difference in the occurrence of associated neurological deficits between the two age groups. This is in contrast to the findings of Ryan and Taylor [21], who found a higher incidence of concomitant spinal cord injury in older patients; however, in their study posterior displacement of the odontoid was predominant in the older patients and that may be the reason for the higher incidence of neurological findings in this age group. There are only few data in the literature concerning the relationship between myelopathy and displacement of the odontoid. In this study neurological impairment was associated with posterior displacement of the fractured odontoid in the majority of the cases in both patient groups $-2 / 3$ patients in the older group and $5 / 7$ patients in younger. This finding corresponds well with the data of Ryan and Taylor [21], who found an incidence of $70 \%$ of posterior displacement in patients with myelopathy. Even though there seems to be enough space available for the spinal cord according to Steele's rule, the cord is at risk if the fractured dens is displaced posteriorly.

Associated neurological impairment is deleterious for older patients. All three patients with post-traumatic neurological deficits in this age group died during the course of treatment. In patients younger than 70 years with neurological deficits, the injury was lethal in two cases out of seven: both patients were older than 60 years

The reported primary in-hospital mortality for elderly patients varies between $0 \%$ and $26.3 \%[5,13,18,20]$ and concomitant medical illness is recognised as a major factor determining early mortality. In this series the in-hospital mortality was slightly higher with $34.8 \%$ (8/23). Concomitant neurological impairment and severe associated injuries were related to death in four patients. The remaining four patients died in the postoperative period; in two of these internal stabilisation had been performed after complicated non-operative treatment.

Failure of stabilisation and/or non-union associated with non-operative treatment of primary undisplaced type II fractures was noted in 5 out of 11 patients in the elderly age group. All five patients were initially treated with a cervical orthosis (Philadelphia collar). In contrast to the findings of Schatzker et al. [22], who found an increasing rate of non-union with an increasing extent of displacement, all these fractures were undisplaced on initial radiographs. Malunion was accepted in one patient despite the findings of Crockard et al. [8], who identified a high risk of secondary myelopathy in malunion and non-union of the odontoid. The patient showed no signs of myelopathy at follow-up and the risks of a pre-emptive strike were not acceptable because of the patient's age. In the younger age group, loss of reduction occurred in three initially dis- 
placed type II and one undisplaced type II and another undisplaced type III fracture. Pseudarthrosis was found in two undisplaced type II and one undisplaced type III injury. Because of these findings we recommend lateral flexion-extension views to determine the stability of an undisplaced fracture to prevent secondary dislocation and possibly the potential for non-union. Unstable fractures should undergo primary internal fixation or be treated in a halo fixator. Although odontoid fractures can be successfully treated with a halo device, as has been shown by Lind et al. [15] as well as by Schweigel [23], there is a high incidence of complications associated with this device, especially in elderly patients $[11,15]$, and therefore primary internal fixation may be the method of choice.

\section{Conclusions}

Fractures of the odontoid in the elderly are associated with a high morbidity and mortality rate, and treatment remains a challenge for the physician in charge. Our results suggest a difference in the fracture personality in geriatric patients as compared to the younger. Associated compromise of the spinal cord and treatment-related complications are less well tolerated than in younger patients. Initially undisplaced but unstable fractures were a main cause for significant complications. On the basis of our experience, we recommend an initially aggressive diagnostic approach with lateral flexion-extension views to detect unstable fractures that are not suitable for non-operative treatment with a cervical orthosis only. Application of a halo device or primary internal stabilisation is recommended.

\section{References}

1. Aebi M, Etter C, Coscia M (1989) Fractures of the odontoid process. Treatment with anterior screw fixation. Spine 14: 1065-1070

2. Amling M, Wening VJ, Posl M, Grote HJ, Hahn M, Delling G (1994) Die Struktur des Axis - Schlüssel zur Struktur der Densfraktur. Chirurgie 65: 964-969

3. Anderson LD, d'Alonzo RT (1974)

Fractures of the odontoid process of the axis. J Bone Joint Surg [Am] 56: 1663-1674

4. Baker SP, Neill BO, Haddon W, Long WB (1974) The injury severity score: a method for describing patients with multiple injuries and evaluating emergency care. J Trauma 14: 187-196

5. Bednar DA, Parikh J, Hummel J (1995) Management of type II odontoid process fractures in geriatric patients: a prospective study of sequential cohorts with attention to survivorship. J Spinal Disord 8: 166-169

6. Chiba K, Fujimura Y, Toyama Y, Takahata T, Nakanishi T, Hirabayashi K (1993) Anterior screw fixation for odontoid fracture: clinical results in 45 cases. Eur Spine J 2: 76-81

7. Clark CR, White AA (1985) Fractures of the dens. J Bone Joint Surg [Am] 67: $1340-1348$

8. Crockard HA, Heilman AE, Stevens JM (1993) Progressive myelopathy secondary to odontoid fractures: clinical, radiological, and surgical features. J Neurosurg 78: 579-586
9. Doherty BJ, Heggeness MH, Esses SI (1993) A biomechanical study of odontoid fractures and fracture fixation. Spine 18: 178-184

10. Frankel H, Hancock DO, Hyslop G, Melzak J, Michaelis LS, Ungar GH, Vernon JDS, Walsh JJ (1969) The value of postural reduction in the initial management of closed injuries of the spine with paraplegia and tetraplegia. Paraplegia 7: 179-192

11. Garfin SR, Botte MJ, Waters RL, Nickel VL (1986) Complications in the use of the halo fixation device. J Bone Joint Surg [Am] 69: 320-325

12. Hadley MN, Dickman CA, Browner CM, Sonntag VKH (1988) Acute traumatic atlas fractures: management and long-term outcome. Neurosurgery 23: 31-35

13. Hanigan WC, Powell FC, Elwood PW, Henderson JP (1993) Odontoid fractures in elderly patients. J Neurosurg 78: $32-35$

14. Hertzenberg JE, Hensinger RN, Dedrick DK, Phillips WA (1989) Emergency transport and positioning of young children who have an injury of the cervical spine. J Bone Joint Surg [Am] 71: 15-22

15. Lind B, Nordwall A, Sihlbom H (1987) Odontoid fractures treated with halovest. Spine 12: 173-177
16. Magerl F, Seeman PS (1986) Stable posterior fusion of the atlas and axis by transarticular screw fixation. In: Kehr P, Weidner A (eds) Cervical spine. Springer, Berlin Heidelberg New York, pp 322-327

17. Mouradian WH, Fietti VG, Chochran GVB, Fielding JW, Young J (1978) Fractures of the odontoid: a laboratory and clinical study of mechanism. Orthop Clin North Am 9: 985-1001

18. Pepin JW, Bourne RB, Hawkins RJ (1985) Odontoid fractures, with special reference to the elderly patient. Clin Orthop 193: 178-183

19. Pointillart V, Lopez Orta A, Freitas J, Vital JM, Senegas J (1994) Odontoid fractures. Eur Spine J 3: 282-285

20. Ryan MD, Henderson JJ (1992) The epidemiology of fractures and fracturedislocations of the cervical spine. Injury 23: $38-40$

21. Ryan MD, Taylor TKF (1993) Odontoid fractures in the elderly. J Spinal Disord 6: 397-401

22. Schatzker J, Rorabeck CH, Waddell JP (1971) Fractures of the dens (odontoid process). J Bone Joint Surg [Br] 53: 392-405

23. Schweigel JF (1987) Management of the fractured odontoid with halo-thoracic bracing. Spine 12: 838-839 